University of Wollongong

Research Online

Faculty of Engineering and Information

Faculty of Engineering and Information

Sciences - Papers: Part A

Sciences

$1-1-2014$

\title{
A novel approach for ramp-rate control of solar PV using energy storage to mitigate output fluctuations caused by cloud passing
}

M J. E Alam

University of Wollongong, mjealam@uowmail.edu.au

K M. Muttaqi

University of Wollongong, kashem@uow.edu.au

D Sutanto

University of Wollongong, soetanto@uow.edu.au

Follow this and additional works at: https://ro.uow.edu.au/eispapers

Part of the Engineering Commons, and the Science and Technology Studies Commons

Research Online is the open access institutional repository for the University of Wollongong. For further information contact the UOW Library: research-pubs@uow.edu.au 


\title{
A novel approach for ramp-rate control of solar PV using energy storage to mitigate output fluctuations caused by cloud passing
}

\author{
Abstract \\ The variability of solar irradiance with a high ramp-rate, caused by cloud passing, can create fluctuation in \\ the PV output. In a weak distribution grid with a high PV penetration, this can create significant voltage \\ fluctuations. Energy storage devices are used to smooth out the fluctuation using traditional moving \\ average control. However, moving average does not control the ramp-rate directly; rather the ramp-rate \\ depends on previous values of PV output. This paper proposes a strategy where the ramp-rate of PV \\ panel output is used to control the PV inverter ramp-rate to a desired level by deploying energy storage \\ (which can be available for other purposes, such as storing surplus power, countering voltage rise, etc.). \\ During the ramping event, the desired ramp-rate is governed by controlling the energy storage based on an \\ inverse relationship with the PV panel output ramp-rate to improve the fluctuation mitigation \\ performance. In contrast to the moving average method, the proposed strategy is able to control the \\ desired ramp-rate independent of the past history of the PV panel output. A dynamic model of the PV- \\ storage integrated system is developed to verify the proposed strategy in the presence of physical device \\ time lags. The proposed strategy is verified using simulation results based on an Australian distribution \\ system. A laboratory experiment is also conducted to validate the concept of the proposed control \\ strategy.
}

\section{Keywords}

solar, novel, pv, energy, storage, mitigate, output, fluctuations, caused, cloud, passing, ramp, control, approach, rate

\section{Disciplines}

Engineering | Science and Technology Studies

\section{Publication Details}

M. Alam, K. Muttaqi \& D. Sutanto, "A novel approach for ramp-rate control of solar PV using energy storage to mitigate output fluctuations caused by cloud passing," IEEE Transactions on Energy Conversion, vol. 29, (2) pp. 507-518, 2014. 


\title{
A Novel Approach for Ramp-rate Control of Solar PV Using Energy Storage to Mitigate Output Fluctuations Caused by Cloud Passing
}

\author{
M. J. E. Alam, Student Member, IEEE, K. M. Muttaqi, Senior Member, IEEE and D. Sutanto, Senior \\ Member, IEEE
}

\begin{abstract}
The variability of solar irradiance with a high ramp-rate, caused by cloud passing, can create fluctuation in the PV output. In a weak distribution grid with a high PV penetration, this can create significant voltage fluctuations. Energy storage devices are used to smooth out the fluctuation using traditional moving average control. However, moving average does not control the ramp-rate directly; rather the ramprate depends on previous values of PV output. This paper proposes a strategy where the ramp-rate of $P V$ panel output is used to control the PV inverter ramp-rate to a desired level by deploying energy storage (which can be available for other purposes, such as storing surplus power, countering voltage rise, etc). During the ramping event, the desired ramp-rate is governed by controlling the energy storage based on an inverse relationship with the $P V$ panel output ramp-rate to improve the fluctuation mitigation performance. In contrast to the moving average method, the proposed strategy is able to control the desired ramp-rate independent of the past history of the PV panel output. A dynamic model of the PV-storage integrated system is developed to verify the proposed strategy in the presence of physical device time lags. The proposed strategy is verified using simulation results based on an Australian distribution system. A laboratory experiment is also conducted to validate the concept of the proposed control strategy.
\end{abstract}

Index Terms- Solar PV, fluctuation, ramp-rate control, energy storage.

\section{INTRODUCTION}

$\mathrm{S}$ OLAR photovoltaic power generation can be highly variable in nature due to the irregularities in the sun irradiance level caused by cloud passing. Although the investigation on PV output variability has been continuing for a long time as evidenced in [1-2], it is still being addressed as an issue of contemporary interest [3], especially with a high penetration level of PV resources. Recent operating experiences from La Ola Island PV plant [4] has revealed that the ramp-rate of the PV output can be as high as $63 \%$ of the rated capacity/minute, whereas it was intended to limit the ramp-rate up to $30 \%$ of the rated capacity /minute [4]. To avoid any negative impact of such a high ramp-rate on the

This work is supported by the Australian Research Council (ARC) and Essential Energy Linkage Grant, LP100100618.

M. J. E. Alam, K. M. Muttaqi and D. Sutanto is with Australian Power Quality and Reliability Center, School of Electrical Computer and Telecommunications Engineering, University of Wollongong, NSW 2522, Australia (e-mail: mjea982@uowmail.edu.au, kashem@uow.edu.au, soetanto@uow.edu.au). distribution system, the PV penetration was limited to $50 \%$ of the PV plant capacity [4]. The one-second resolution irradiance data collected from Oahu Island by NREL [5] shows that the irradiance level can fluctuate with a ramp-rate of more than $50 \%$ between two consecutive measurements. A PV output ramp-rate of $20 \%$ of the rated capacity/second is recorded in a study [6] conducted on a system in Mesa del Sol, New Mexico. In Australia, the Commonwealth Scientific and Industrial Research Organisation (CSIRO) has reported [7] that the PV output ramp-rates can be up to $8 \%$ of the rated capacity/second at various locations. With a high penetration of grid-connected PV resources in weak radial distribution systems, such high ramp-rate variations of the PV output can introduce significant voltage fluctuations [8]. Therefore, ramprate control strategies to reduce fluctuations in PV outputs and the resulting voltage fluctuations in PV integrated distribution systems are necessary in order to increase the PV penetration level in the networks.

Different kinds of energy storage technologies have been proposed for smoothing of PV output, such as, electric doublelayer capacitor (EDLC) [9-11], superconducting magnetic energy storage [12], fuel cell [13], and battery energy storage [14-15]. A moving average based ramp-rate control is proposed in [9] for smoothing PV output fluctuations using EDLC. The moving average method was also used in [14] for controlling battery energy storage to reduce PV fluctuations. An exponential moving average has been used in [16] that gives more weight on the recent values of the fluctuating PV output. A modified Euler type moving average model is proposed in [11] for prediction of moving average values for a hybrid system with PV, fuel cell, EDLC and battery. Controlling an energy storage device using traditional moving average method can reduce PV output fluctuation, but it may not necessarily control the PV output to a desired ramp-rate. Also, a moving average with a long averaging window would require a storage device to operate to match the difference between the actual PV output and the moving average, even if the actual PV output is not significantly fluctuating. The battery and charging facility available in an electric-vehicle has been used in [15] to mitigate the short-term intermittency using a high-pass filter for fluctuation mitigation. In this method, the ramp-rate of PV inverter is limited using the characteristics of the filter, such as the corner frequency. A dynamic filtering controller and dynamic rate limiter approach 
is used in [17] for smoothing of PV and wind power generation fluctuations.

In [18], the power delivered/absorbed by energy storage for ramp-rate control is determined using a battery State of Charge (SoC) versus allowable ramp-rate droop characteristic for generic renewable resources, where the allowable ramprate is related to the $\mathrm{SoC}$, but not directly related to the renewable resource ramp-rate. An application of this strategy for a utility scale PV plant is demonstrated in [19]. Fluctuation mitigation using moving average control and a first-order low pass filter is presented in [20] where the SoC of the energy storage device is maintained within a range by modifying the energy storage power output using a gain parameter, which requires tuning. The impact of different storage time constants has also been investigated using time constants up to 30 seconds. Authors in [6] have applied both ramp-rate control and moving average method for intermittency mitigation of the aggregate output of a distribution system with several distributed resources including an energy storage system. There is no unique strategy for PV output smoothing, as it depends on many factors including cost and response time of the compensating resource and system operation policy [6]. Also, the delay in data transmission can cause less smooth output or may even add more fluctuation to the aggregate output [6]. However, if the fluctuation is mitigated at the PV connection point with local information, the transmission of data would not be necessary.

The contribution of this paper is to propose a new method for mitigation of PV inverter output fluctuation by ramp-rate control using energy storage. The energy storage system may be available for other purposes, such as storing excess energy for use when the sun is not available, mitigating voltage rise, etc [21]. The novelty of the proposed approach is an algorithm to control the ramp-rate of the PV output fluctuation using the appropriate strategies during the ramping and post-ramping event. During a ramp-down or ramp-up event, the energy storage system is controlled based on an inverse characteristic of the desired ramp-rate of PV inverter with respect to the ramp-rate of the PV panel output to improve the fluctuation mitigation performance. Once the ramping event is over, the energy storage system will be controlled using a SoC droop characteristic to consider the available capacity in selecting the desired ramp-rate. Unlike the traditional moving average method, the proposed strategy does not have a memory effect and therefore the storage devices can be controlled according to the requirement at each instant of time without being influenced by the PV panel output at the previous instants or without affecting the compensating power at a future time instant. A dynamic model of the PV-storage integrated system is developed and integrated with the distribution network model to test the validity of the proposed strategy in a dynamic environment with physical device time-lags. Voltage fluctuation mitigation achieved by applying the proposed control strategy is also investigated. The proposed control strategy is verified using a daylong quasi-steady-state and dynamic simulation based on an Australian distribution system and also using a basic experimental setup.

\section{Limitations of Traditional MOVIng AVERAGE METHOD IN RAMP-RATE CONTROL}

Traditionally, moving average is used to smooth out a fluctuating variable. Energy storage device has been controlled by moving average method for smoothing PV output fluctuations in $[14,20]$. Although this is a traditionally accepted way to reduce the fluctuations in PV output, it requires the energy storage device to inject/absorb power even if the PV output is not fluctuating significantly. Also, such moving average strategy does not control the ramp-rate directly. These points are discussed further below.

It is well-known that moving average has a memory effect. Depending on the length of the averaging window, a moving average would highly depend on the past history and therefore, may be significantly different than the present value of the fluctuating variable. For PV output smoothing, the integrated storage device will have to operate to make-up for the aforementioned difference between the actual PV output and the moving average. Numerically, a moving average with a $w$-length window contains only $(1 / w) \%$ of the present value of the fluctuating variable. A realistic PV output from Oahu Island, Hawaii on the $18^{\text {th }}$ of March 2010, available from NREL [5] and its 20-min moving average is shown in Fig. 1. Although the PV output does not fluctuate significantly during the time periods in the red circles, the moving average values during these times still deviate significantly from the actual PV outputs due to the memory effect of the moving average method. To make-up for this deviation, energy storage device needs to operate more than necessary.

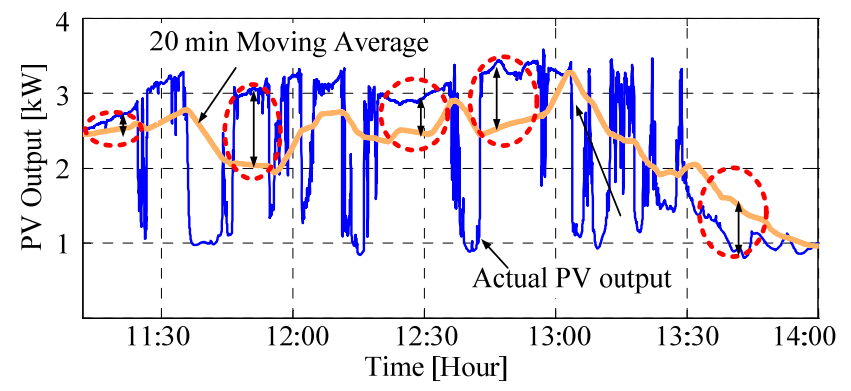

Fig. 1. Actual PV output and a 20-min moving average.

Further, with a given window length $w$, the moving average method may not provide a desired ramp-rate; rather the ramprate will depend on the past history of the fluctuating PV output. The ramp-rate of the moving average of a variable PV output at the $k$-th time instant can be defined using the following expression.

$$
\begin{aligned}
\operatorname{MoRR}(k) & =\frac{1}{w} \times \frac{\sum_{i=0}^{w-1} P_{D C}(k-i)-\sum_{i=0}^{w-1} P_{D C}(k-1-i)}{t(k)-t(k-1)} \\
& =\frac{1}{w} \times \frac{P_{D C}(k)-P_{D C}(k-w)}{t(k)-t(k-1)}
\end{aligned}
$$

where, $\operatorname{MoRR}(k)$ is the ramp-rate of the moving average of PV panel DC output, $w$ is the length of the moving average window in terms of the number of data points, $P_{\mathrm{DC}}$ is the PV panel DC output and $t(k)$ is the time corresponding to the $k$-th time instant. Observing (1), it is clear that the ramp-rate obtained by following a moving average of the PV output 
depends on the PV output at the $k$-th and ( $k$-w)-th instant. Although, a significantly low ramp-rate can be obtained by following a moving average with a long window, it is not directly related to the actual desired level.

\section{The Proposed RAmP-RATE CONTROL Strategy}

\section{A. Concept of the Proposed Ramp-rate Control Strategy}

In the proposed ramp-rate control strategy, a compensation power will be added with the PV panel DC power to control the ramp-rate of the PV inverter output within a desired level at any instant of time. The basic concept of ramp-rate control strategy is explained in Fig. 2.

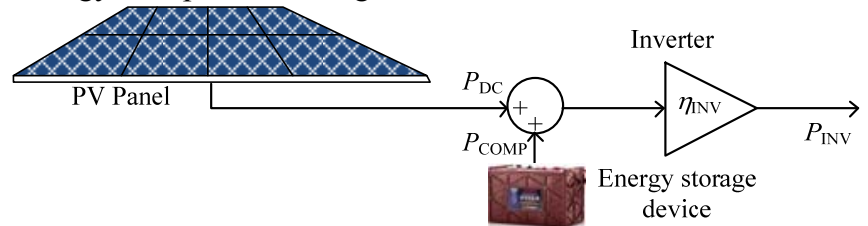

Fig. 2. Conceptual schematic of the proposed ramp-rate control strategy.

Based on Fig. 2, the PV inverter output $P_{\mathrm{INV}}$ can be obtained from the $\mathrm{PV}$ panel DC power $P_{\mathrm{DC}}$ and the compensation power $P_{\mathrm{COMP}}$ using the following expression.

$$
P_{\mathrm{INV}}=\eta_{\mathrm{INV}} \times\left(P_{\mathrm{DC}}+P_{\mathrm{COMP}}\right)
$$

In Fig. 2 and (2), $\eta_{\mathrm{INV}}$ is the inverter efficiency. Taking time derivative of (2) at both sides, the ramp-rate of $P_{\mathrm{INV}}$ can now be related with the ramp-rate of $P_{\mathrm{COMP}}$ and $P_{\mathrm{DC}}$, as given in (3).

$$
\frac{d P_{\mathrm{INV}}}{d t}=\eta_{\mathrm{INV}} \times\left[\frac{d P_{\mathrm{DC}}}{d t}+\frac{d P_{\mathrm{COMP}}}{d t}\right]
$$

where, $\frac{d P_{\mathrm{INV}}}{d t}$ is the $\mathrm{PV}$ inverter output ramp-rate, $\frac{d P_{\mathrm{DC}}}{d t}$ is the PV panel DC power output ramp-rate, and $\frac{d P_{\mathrm{COMP}}}{d t}$ is the compensation power ramp-rate.

To control the ramp-rate of the PV inverter output within a desired level, the ramp-rate of $P_{\text {COMP }}$ can be controlled using the expression derived from (3), as given below.

$$
\frac{d P_{\mathrm{COMP}}}{d t}=\frac{1}{\eta_{\mathrm{INV}}} \times\left[\left.\frac{d P_{\mathrm{INV}}}{d t}\right|_{\text {des }}-\eta_{\mathrm{INV}} \times \frac{d P_{\mathrm{DC}}}{d t}\right]
$$

where, $\left.\frac{d P_{\mathrm{INV}}}{d t}\right|_{\text {des }}$ is the desired ramp-rate of the PV inverter, which will be negative during a ramp-down event and positive during a ramp-up event.

The expression given in (4) is the basic control equation that will be followed to control the ramp-rate of PV inverter output. However, the following modifications are made to accommodate practical situations.

(a) To allow for the slow variations of $P_{\mathrm{DC}}$ with the progress of the day, a dead-band function ' $f$ ' is incorporated with (4) that will force the ramp-rate of $P_{\mathrm{DC}}$ to be zero if it is within an acceptable limit, defined using the desired ramp-rate of $P_{\mathrm{INV}}$, as shown below.

$$
f\left(\frac{d P_{\mathrm{DC}}}{d t}\right)=\left\{\begin{array}{l}
0, \text { if } \eta_{\mathrm{INV}} \times\left|\frac{d P_{\mathrm{DC}}}{d t}\right| \leq\left.\frac{d P_{\mathrm{INV}}}{d t}\right|_{\text {des }} \\
\frac{d P_{\mathrm{DC}}}{d t}, \text { otherwise }
\end{array}\right.
$$

(b) Observing (4) it is apparent that when the ramp-rate of $P_{\mathrm{DC}}$ is zero, considering the dead-band function mentioned in modification ( $a$ ), the ramp-rate of $P_{\text {COMP }}$ will be governed by the desired ramp-rate of $P_{\mathrm{INV}}$. However, when the ramp-rate of $P_{\mathrm{DC}}$ is zero, then if $P_{\mathrm{COMP}}$ has already attained such a level that removal of $P_{\mathrm{COMP}}$ would not create an unacceptable fluctuation in $P_{\mathrm{INV}}$, then $P_{\mathrm{COMP}}$ does not need to be changed anymore. To accommodate this, a switching function $S$, as given below, is incorporated with (4).

$$
S=\left\{\begin{array}{l}
0, \text { if }\left|P_{\mathrm{COMP}}\right|<\left.\frac{d P_{\mathrm{INV}}}{d t}\right|_{\text {des }} \text { and } f\left(\frac{d P_{\mathrm{DC}}}{d t}\right)=0 \\
1, \text { otherwise }
\end{array}\right.
$$

The modified control equation can be described using the expression below.

$\frac{d P_{\mathrm{COMP}}}{d t}=S \times\left[\frac{1}{\eta_{\mathrm{INV}}} \times\left\{\left.\frac{d P_{\mathrm{INV}}}{d t}\right|_{d e s}-\eta_{\mathrm{INV}} \times f\left(\frac{d P_{\mathrm{DC}}}{d t}\right)\right\}\right]$

The inverter efficiency $\eta_{\mathrm{INV}}$ will depend on the power output of the inverter. The efficiency curve for a given inverter over a range of operating power can be obtained from the manufacturer or developed through testing. As the desired $P_{\mathrm{INV}}$ at any given instant is known, $\eta_{\mathrm{INV}}$ at the desired $P_{\mathrm{INV}}$ can be taken from the efficiency curve and can be used in (7) to control the ramp-rate of $P_{\mathrm{COMP}}$ at the necessary level.

Considering a discrete time representation, the ramp-rate of $P_{\mathrm{DC}}$ at the $k$-th instant can be determined using the expression below.

$$
\frac{d P_{\mathrm{DC}}}{d t}(k)=\frac{\left[P_{\mathrm{DC}}(k)-P_{\mathrm{DC}}(k-1)\right]}{t(k)-t(k-1)}
$$

where, $t(k)$ is the time at the $k$-th instant.

The value of the switching function is also incorporated with $P_{\text {COMP }}$ to force it to zero when the conditions of $S=0$ are satisfied, as given in (6). $P_{\text {COMP }}$ at the $k$-th instant can be obtained using (9).

$$
P_{\text {COMP }}(k)=S \times\left[P_{\text {COMP }}(k-1)+\frac{d P_{\text {COMP }}}{d t}(k) \times\{t(k)-t(k-1)\}\right](9)
$$

To illustrate the proposed ramp-rate control strategy, a fictitious PV output fluctuation shown in Fig. 3(a) is used, where the PV panel output decreases at a ramp-rate of $\mathrm{PVRR}_{1}$ $\mathrm{kW} / \mathrm{sec}$ from time $t_{1}$ to $t_{2}$, remains constant at the level reached at time $t_{2}$ up to time $t_{3}$, and again increases from time $t_{3}$ to time $t_{4}$ at a ramp-rate of $P_{V R R} \mathrm{~kW} / \mathrm{sec}$. After reaching time $t_{4}$, the $\mathrm{PV}$ output remains constant. To control the ramp-rate of $P_{\mathrm{INV}}$, (7) and (9) are used to produce the appropriate amount of $P_{\text {Comp. }}$ The desired ramp-rate of $P_{\text {INV }}$ is defined as the Maximum Allowable Ramp-rate (MARR) in W/sec. To apply the proposed strategy to any size of PV plant, the ramp-rate units can also be defined in \% of the rated PV capacity/sec. Before time $t_{1}, P_{\mathrm{DC}}$ remains at a stable state. Therefore, the ramp-rate of $P_{\mathrm{COMP}}$ is zero according to (7), and remains zero. From time $t_{1}$ to $t_{2}, P_{\mathrm{DC}}$ sharply decreases with a ramp-rate of 
$\mathrm{PVRR}_{1}$. During this time the ramp-rate of $P_{\mathrm{COMP}}$ is determined using $\mathrm{PVRR}_{1}$ and MARR. At time $t_{2}, \mathrm{PVRR}_{1}$ becomes zero, but $P_{\text {COMP }}$ is not zero yet. Therefore, the ramp-rate of $P_{\text {COMP }}$ from time $t_{2}$ to $t_{3}$ is determined using MARR only. From time $t_{3}$ to $t_{4}, P_{\mathrm{DC}}$ sharply increases with a ramp-rate of $\mathrm{PVRR}_{2}$. During this time, $P_{\mathrm{COMP}}$ is controlled with a ramp-rate determined using $\mathrm{PVRR}_{2}$ and MARR. After time $t_{4}, \mathrm{PVRR}_{2}$ becomes zero, however, $P_{\text {COMP }}$ is not zero yet. Therefore, from time $t_{4} P_{\text {COMP }}$ is controlled using MARR only. At time $t_{5}$, $P_{\text {COMP }}$ becomes zero and the ramp-rate of $P_{\mathrm{DC}}$ is also zero. Therefore, the ramp-rate of $P_{\text {COMP }}$ is zero after $t_{5}$ which keeps $P_{\text {COMP }}$ at zero.
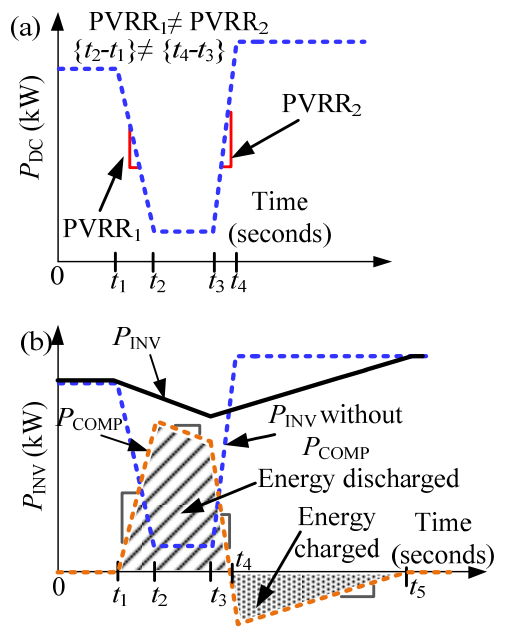

Fig. 3. An illustration of the proposed ramp-rate control strategy. (a) A hypothetical PV output fluctuation. (b) PV inverter output with appropriately controlled $P_{\mathrm{COMP}}$ to limit the $P_{\mathrm{INV}}$ ramp-rate within a desired level.

For moving average control, $P_{\mathrm{COMP}}$ at a given $k$-th instant depends on the previous values of $P_{\mathrm{DC}}$ within the averaging window, $w$, as given below.

$$
P_{\text {COMP }}(k)=\frac{\sum_{i=0}^{w-1} P_{\mathrm{DC}}(k-i)}{w}-P_{\mathrm{DC}}(k)
$$

Therefore, if moving average is applied to control the ramp-rate of the fluctuation shown in Fig. 3(a), then $P_{\text {COMP }}$ at $t>t_{1}$ will actually depend on the $P_{\mathrm{DC}}$ values before $t_{1}$. It will not directly depend on the required $P_{\mathrm{COMP}}$ to control the ramp-rate at a desired level. According to (10), $P_{\text {COMP }}$ is only controllable using the length of the averaging window $w$. The higher the number $w$ is chosen, the more is the smoothing effect. However, if a high $w$ is chosen for improving fluctuation mitigation performance at the $k$-th instant, it not only impacts the $P_{\text {COMP }}$ at the $k$-th instant, but also at all the future time instants. For example, if $w$ is increased by $\Delta w$ to increase the smoothing effect at the $k$-th instant, then at any future $(k+j)$-th instant, the deviation of $P_{\text {COMP }}$ due to the increase of $w$ (i.e., $\Delta w$ ) will be,

$$
\Delta P_{\mathrm{COMP}}(k+j)=\left|\frac{\sum_{i=0}^{w+\Delta w-1} P_{\mathrm{DC}}(k+j-i)}{w+\Delta w}-\frac{\sum_{i=0}^{w-1} P_{\mathrm{DC}}(k+j-i)}{w}\right|
$$

The deviation $\Delta P_{\text {COMP }}$ at the $(k+j)$-th instant is solely due to the increase of $w$ at the $k$-th instant. For a given $\Delta w$, this deviation will remain in effect for all future time instants even if it is not necessary because of acceptable variations in $P_{\mathrm{DC}}$.

In contrast, according to the proposed ramp-rate control strategy, the amount of $P_{\text {COMP }}$ to control the ramp-rate at a given $k$-th instant can be governed by the desired ramp-rate of $P_{\text {INV }}$ for the $k$-th instant only and it does not impact the future ramp-rates. According to (9), $P_{\mathrm{COMP}}$ at the $k$-th time instant is,

$$
P_{\mathrm{COMP}}(k)=S \times\left[P_{\mathrm{COMP}}(k-1)+\phi\left(\left.\frac{d P_{\mathrm{INV}}}{d t}(k)\right|_{\text {des }}\right)\right]
$$

In (12), $\phi(\cdot)$ denotes a function that determines the ramprate of $P_{\mathrm{COMP}}$ for obtaining the desired ramp-rate of $P_{\mathrm{INV}}$ at the given ramp-rate of $P_{\mathrm{DC}}$. The value of $\phi(\cdot)$ is obtained using (7). As the proposed strategy does not have a memory effect, $P_{\text {COMP }}$ can be changed at each instant dynamically based on the requirement. This advantage is used in this paper to improve the fluctuation mitigation performance.

\section{B. Improvement of the Fluctuation Mitigation Performance}

For a given PV output fluctuation, the duration of the ramping event is inversely proportional to the ramp-rate of the PV output, because the higher the ramp-rate, the faster the PV output changes from one stable state to another stable state. As the time duration for a high-rate ramping event is very short, the amount of energy needs to be used for ramp-rate control is small. Therefore, during the ramping event, the MARR can be reduced in an inverse proportion to the PV panel output ramprate (PVRR) to improve the fluctuation mitigation performance without discharging a significant amount of storage capacity. Such an inverse characteristic is given in (13) and shown in Fig. 4(a).

$$
\operatorname{MARR}_{\rho}(k)=\left\{\begin{array}{l}
|\operatorname{PVRR}(k)|, \text { if }|\operatorname{PVRR}(k)|<\mathrm{RR}_{\text {lim }} \\
\frac{\gamma}{|\operatorname{PVRR}(k)|}, \text { if }|\operatorname{PVRR}(k)| \geq \mathrm{RR}_{\text {lim }}
\end{array}\right.
$$

In (13), $\mathrm{MARR}_{\rho}$ is the inverse characteristic based desired ramp-rate, to be applied during the ramping event and $\gamma$ is a factor to control the degree of inverse characteristic; $R_{\text {lim }}$ is a threshold of ramp-rate of $P_{\mathrm{DC}}$ beyond which the inverse characteristic is applied. $R_{\text {lim }}$ should be set to a value higher than the ramp-rate of slow variations of $P_{\mathrm{DC}}$ to allow $P_{\mathrm{INV}}$ to vary with the progress of the day. Once the ramping event is over, the $P_{\text {COMP }}$ can be brought to zero with an MARR determined using a SoC droop characteristic as given by (14) and shown in Fig. 4(b).

$$
\operatorname{MARR}_{\sigma}(k)=\left\{\begin{array}{c}
M_{M_{\text {min }},} \text { if }|\Delta \mathrm{SoC}(k)|<\operatorname{SoC}_{\mathrm{LB}} \\
\mathrm{MARR}_{\text {min }}+\frac{D B_{\mathrm{MARR}}}{D B_{\mathrm{SoC}}} \times\left[|\Delta \mathrm{SoC}(k)|-\mathrm{SoC}_{\mathrm{LB}}\right], \\
\quad \text { if } \operatorname{SoC}_{\mathrm{LB}} \leq|\Delta \operatorname{SoC}(k)| \leq \mathrm{SoC}_{\mathrm{UB}} \\
\mathrm{MARR}_{\text {max }}, \text { if }|\Delta \mathrm{SoC}(k)|>\mathrm{SoC}_{\mathrm{UB}}
\end{array}\right.
$$

In (14), $\mathrm{MARR}_{\sigma}$ is a SoC droop based desired ramp-rate, to be applied once the ramping event is over; $D B_{\mathrm{MARR}}$ and $D B_{\mathrm{SoC}}$ are the dead-bands of MARR and SoC, respectively; $\mathrm{SoC}_{\mathrm{LB}}$ and $\mathrm{SoC}_{\mathrm{UB}}$ are the lower and upper bands of $\mathrm{SoC}$, respectively, and $|\Delta \mathrm{SoC}(k)|$ is the absolute value of the deviation between $\mathrm{SoC}(k-1)$ and a user defined reference $\mathrm{SoC}_{\text {ref. }}$ Using the absolute deviation makes the droop 
characteristic applicable for change of SoC in either direction.

(a)

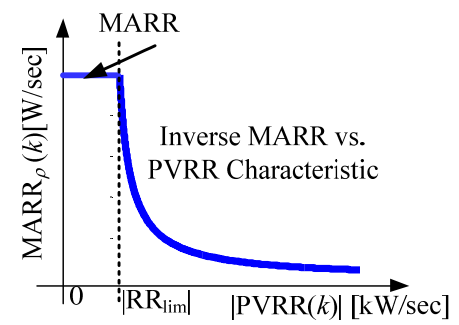

(b)

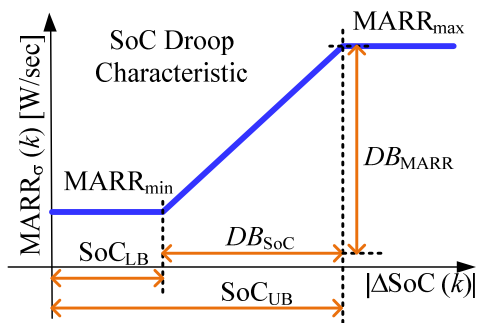

(c)
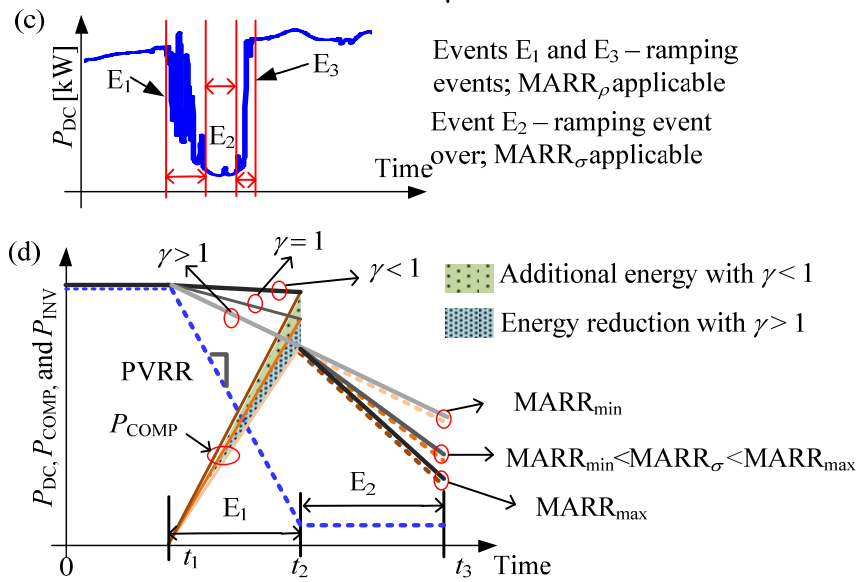

Fig. 4. Ramping event dependent selection of MARR. (a) During the ramping event. (b) After the ramping event. (c) Application of $\mathrm{MARR}_{\rho}$ and $\mathrm{MARR}_{\sigma}$ (d) The effect of $\gamma$ and MARR versus SoC droop on ramp-rate control.

Fig. 4(c) identifies the ramping events in a real PV output fluctuation and shows the event driven application of $\mathrm{MARR}_{\rho}$ and $\mathrm{MARR}_{\sigma}$ to control the ramp-rates. $\mathrm{SoC}_{\mathrm{LB}}$ defines the amount of energy available for controlling the ramp-rate at $\mathrm{MARR}_{\text {min }}$ before entering the droop characteristic. Therefore, $\mathrm{SoC}_{\mathrm{LB}}$ should be set to a value that represents a sufficient

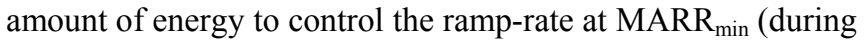
the worst-case fluctuation) for a certain amount of time that allows for any back up power to come online or any sensitive load to be shut down safely. $\mathrm{SoC}_{\mathrm{UB}}$ should be set up to a value that represents a substantial portion of the energy needed to control the ramp-rate (during the worst-case fluctuation) before exceeding the saturation limit of the droop characteristic $\left(\mathrm{MARR}_{\max }\right)$.

The effect of the parameter $\gamma$ in (13) and the parameters $\mathrm{MARR}_{\text {min }}$ and $M A R R_{\text {max }}$ in (14) on the fluctuation mitigation performance is shown in Fig. 4(d) using a fictitious PV fluctuation containing a ramping event $\mathrm{E}_{1}$ (time $t_{1}$ to $t_{2}$ ) at a ramp-rate PVRR, followed by a low $\mathrm{PV}$ event $\mathrm{E}_{2}$ (time $t_{2}$ to $t_{3}$ ). During the event $\mathrm{E}_{1}, \mathrm{MARR}_{\rho}$ is applicable which is determined by $\gamma$. If $\gamma=1, \mathrm{MARR}_{\rho}$ is in direct inverse relation with the ramp-rate of $P_{\mathrm{DC}}$. If $\gamma<1$, the degree of the inverse characteristic increases, and therefore, $P_{\mathrm{INV}}$ is improved compared to $\gamma=1$. However, this will be performed at the expense of additional energy discharged from the storage device as shown in Fig. 4(d) using the shaded region. If $\gamma>1$, the degree of the inverse characteristic decreases, and therefore, $P_{\mathrm{INV}}$ is reduced compared to $\gamma=1$, but at the same time less amount of energy is discharged from the storage device, as shown in Fig. 4(d). Although for high ramp-rate events, the variation of storage energy discharge is not significant, it provides the user a control over the fluctuation mitigation performance of the proposed strategy.

During the event $\mathrm{E}_{2}, P_{\mathrm{COMP}}$ slowly decreases at $\mathrm{MARR}_{\sigma}$ determined from the SoC droop characteristic in (14). For a given fluctuation, $\mathrm{MARR}_{\text {min }}$ is selected as $\mathrm{MARR}_{\rho}$ so that $P_{\mathrm{INV}}$ can be reduced at the same ramp-rate as it reduces during event $E_{1}$, which provides a smooth transition in ramp-rate control from event $E_{1}$ to $E_{2}$. However, if $|\Delta S o C|$ is higher than $\mathrm{SoC}_{\mathrm{LB}}$, then $\mathrm{MARR}_{\sigma}$ is increased and therefore, $P_{\mathrm{INV}}$ reduces at a higher ramp-rate as shown in Fig. 4(d). MARR max $_{\text {in }}$ (14) needs to be set to a value that allows for the slow variations of $P_{\mathrm{DC}}$, as mentioned for selecting $\mathrm{RR}_{\lim }$ in (13).

The discussions presented above provide only basic guidelines for selection of the control parameters for the proposed strategy. In general, these parameters are user defined and can vary depending on the scenario.

\section{Energy Utilization for the Control of Ramp-rate}

The amount of energy to be utilized by an energy storage device for controlling the ramp-rate will mainly depend on the PV panel output power, $P_{\mathrm{DC}}$, just prior to start of the fluctuation, and the maximum allowable ramp-rate, MARR. A relation of the energy usage for ramp-rate control to the rated output of a PV panel is established and discussed below using Fig. 5.

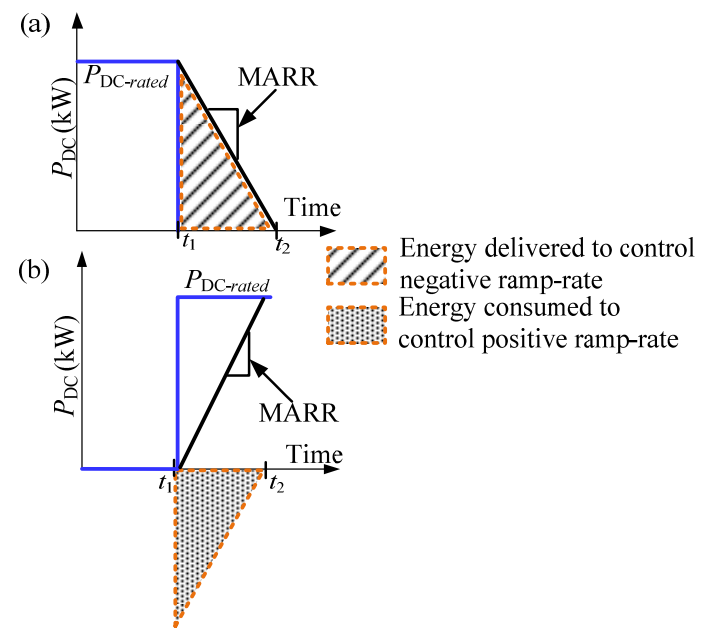

Fig. 5. Energy utilization in the proposed ramp-rate control strategy. (a) During negative ramp-rate control; (b) During positive ramp-rate control.

To consider a worst case fluctuation, a PV output power having a sudden fall from the rated value of $\mathrm{P}_{\mathrm{DC} \text {-rated }}$ to zero at time $t_{1}$ is shown in Fig. 5(a). In this case it is assumed that $P_{\mathrm{DC}}$ does not return to its previous value due to a likely phenomenon of a sustained cloudy period, after time $t_{1}$. According to the proposed strategy, the PV inverter output will be slowly reduced at the maximum allowable ramp-rate 
MARR and will become zero at time $t_{2}$, instead of suddenly dropping to zero. The value of MARR will be determined depending on the situation as shown in Fig. 4. The energy to be discharged by the storage device in controlling the ramprate is shown in Fig. 5(a) using a shaded area. A similar type of worst case scenario for positive ramp-rate is shown in Fig. 5(b), where the PV output suddenly increases from zero to $\mathrm{P}_{\mathrm{DC}-\text { rated }}$ at time $t_{1}$. In this case, the positive ramp-rate of the $P_{\mathrm{INV}}$ is controlled by charging the energy storage with certain amount of energy, as indicated using a shaped area in Fig. 5 (b). The energy utilized for ramp-rate control, $E_{\mathrm{RRC}}(\mathrm{kWh})$ can be derived using the expression given below.

$$
E_{\mathrm{RRC}}=\frac{\sum_{i=1}^{N_{\text {tot }}}\left(P_{\mathrm{DC}-\text { rated }}-i \times \mathrm{MARR}\right)}{3600}
$$

where, $N_{\text {tot }}$ is the total number of time-steps between time $t_{1}$ (seconds) and $t_{2}$ (seconds), which can be determined using,

$$
N_{\text {tot }}=\frac{P_{\text {DC-rated }}}{\text { MARR }}
$$

In (15a), 3600 is used to bring the unit to $\mathrm{kWh}$, as the calculations are being performed in per second unit. A plot of the $E_{\mathrm{RRC}}$ for rated PV capacities up to $5 \mathrm{~kW}$ is derived using (15) for different values of MARR and is shown in Fig. 6. Increase of energy utilization for ramp-rate control with increase in PV capacity and decrease in MARR is observed in Fig. 6.

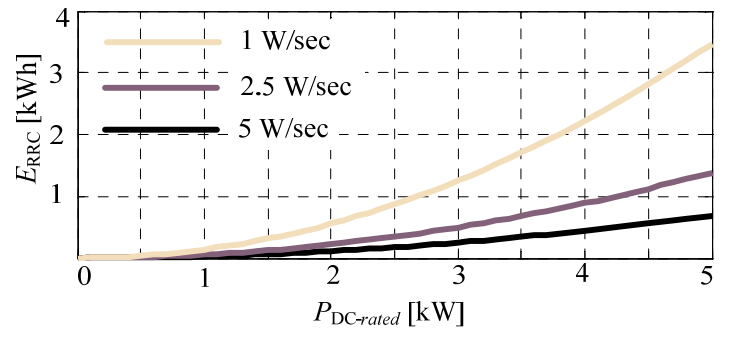

Fig. 6. Variations of the energy utilization for ramp-rate control with different rated PV output at different MARR.

Instead of using $\mathrm{P}_{\mathrm{DC} \text {-rated, }} P_{\mathrm{DC}}(k)$ can be used in (15) to determine the energy required to control the ramp-rate from the present value of $P_{\mathrm{DC}}$. The amount of energy determined in this way can be identified as an Energy Buffer ( $\left.E_{\text {Buff }}\right)$ to approximately check the minimum amount of capacity need to be present in the storage to control the ramp-rate according to the proposed strategy.

\section{The Flow Chart of the Proposed Control Strategy}

The flowchart of the proposed ramp-rate control strategy for a given $k$-th time instant is shown in Fig. 7. The ramp-rate of $P_{\mathrm{DC}}$ at the $k$-th instant $\operatorname{PVRR}(k)$ is calculated using (8), and based on this $\mathrm{MARR}_{\rho}$ is calculated using (13). If $\operatorname{PVRR}(k)$ is equal to or higher than $\mathrm{MARR}_{\rho}, S$ is set to 1 and the ramp-rate of $P_{\text {COMP }}$ is determined using (7) and in this case the desired ramp-rate is replaced with $\operatorname{MARR}_{\rho}$. If $\operatorname{PVRR}(k)$ is found lower than $\mathrm{MARR}_{\rho}$, then a test is performed to find if removal of $P_{\text {COMP }}$ would create an unacceptable fluctuation in $P_{\mathrm{INV}}$. If 'Yes', then $S$ is set to 1 and the ramp-rate of $P_{\text {COMP }}$ is determined using (7), but in this case the desired ramp-rate is replaced with $\mathrm{MARR}_{\sigma}$, determined from (14). If 'No', then the ramp-rate of $P_{\text {COMP }}$ is determined using (7) with $S=0$. The ramp-rate of $P_{\mathrm{COMP}}(k)$ is applied to determine $P_{\mathrm{COMP}}(k)$ using (9). With the value of $P_{\mathrm{COMP}}(k)$ obtained, the present level of $\mathrm{SoC}$ is checked. If it is found within the lower $\left(\mathrm{SoC}_{\mathrm{LL}}\right)$ and upper $\left(\mathrm{SoC}_{\mathrm{UL}}\right)$ limits of $\mathrm{SoC}$, obtained using the Maximum Depth of Discharge $\left(\mathrm{DoD}_{\max }\right)$, the Maximum State of Charge $\left(\mathrm{SoC}_{\max }\right)$, and buffer energy $\mathrm{E}_{\mathrm{Buff}}$, then a charge/discharge operation is performed depending on the sign of $P_{\mathrm{COMP}}(k)$. According to the proposed strategy, a +ve sign means discharge, and -ve sign means charge. Once the discharging/charging decision for the time instant is made and the storage is put into operation, the control system proceeds with a transition into the next time instant.

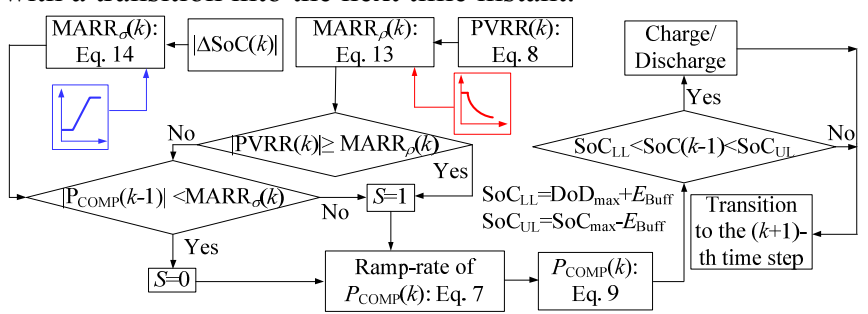

Fig. 7. Flow chart of the proposed ramp-rate control strategy.

Although this paper has mainly concentrated on the application of battery energy storage, the fundamental idea of ramp-rate control proposed in this paper would be applicable for other type of energy storage (such as ultra-capacitor).

\section{E. Dynamic Model of PV-Storage Integrated System}

The development of a dynamic model is necessary to understand the performance of the proposed strategy in the context of practical system components that are subject to physical device time lags. Detailed switching models of the power electronic converters are used in power-electronics based investigations where sub-cycle phenomena are of interest. However, for the scope of the investigations of this paper, such fast dynamics are not of interest. Therefore, a simplistic dynamic model of the PV-storage integrated system is developed, as shown in Fig. 8, that represents the time-lag related to the associated devices and components.

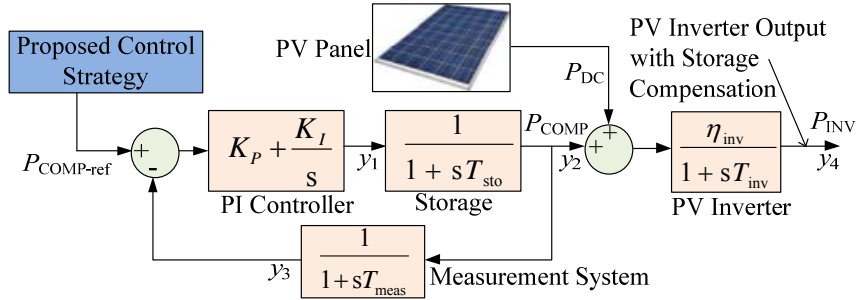

Fig. 8. A dynamic model of the PV-storage integrated system to consider the effect of physical device time-lags.

The dynamic model consists of four states which are the PI controller output $\left(y_{1}\right)$, the storage power output $\left(y_{2}\right)$, storage power output measurement signal $\left(y_{3}\right)$, and the PV inverter output $\left(y_{4}\right)$. The state equations are given below.

$$
\begin{gathered}
\frac{d y_{1}}{d t}=-K_{P} \times \frac{1}{T_{\text {meas }}} \times\left(y_{2}-y_{3}\right)+K_{I} \times\left(P_{\text {COMP-ref }}-y_{3}\right) \\
\frac{d y_{2}}{d t}=\frac{1}{T_{\text {sto }}} \times\left(y_{1}-y_{2}\right)
\end{gathered}
$$




$$
\begin{gathered}
\frac{d y_{3}}{d t}=\frac{1}{T_{\text {meas }}} \times\left(y_{2}-y_{3}\right) \\
\frac{d y_{4}}{d t}=\frac{1}{T_{\text {inv }}} \times\left(\eta_{\text {inv }}\left[P_{\mathrm{DC}}+y_{2}\right]-y_{4}\right)
\end{gathered}
$$

where, $P_{\text {COMP-ref }}$ is the reference to the PI controller; $T_{\text {inv }}$ is the inverter time constant; $T_{\text {sto }}$ is the storage time constant; $T_{\text {meas }}$ is the storage output measurement circuit time delay; $K_{P}$ and $K_{I}$ proportional and integral gain of the PI controller.

It is necessary that the energy storage device responds to the charging/discharging commands as fast as possible to control the ramp-rate satisfactorily. Studies have shown that battery energy storage devices, such as $\mathrm{NaS}$, Li-ion, and Valve-Regulated Lead-Acid (VLRA) batteries, have response time in the order of milliseconds [22-23]. Therefore, it is expected that with an appropriate selection of the energy storage device, the ramp-rate can be controlled according to the requirements. Using the developed dynamic model, the impact of different storage response times on ramp-rate control can be investigated.

The PI controller is tuned to have a low rise time so that the fast response time of the storage device can be effectively used for fluctuation mitigation. The initial controller parameters are obtained using the open-loop frequency response of the linearized plant model. The tuning task is performed with the aid of Simulink Automatic PID tuner [24] that performs the initial tuning based on a reference tracking algorithm while keeping a trade-off between performance and robustness. Once the initial parameters are obtained, further tuning is performed to reduce the rise time.

This paper has mainly discussed the concept of the proposed strategy and its system level application. To carry out a component level detailed design, practical issues, such as battery power losses, heat generated, and DC-link voltage fluctuations caused by high current pulses during high-ramp rate operations, need to be considered.

\section{Application Example of the Proposed Ramp-RATE CONTROL STRATEGY}

To analyze the performance of the proposed strategy in a distribution network environment, a low voltage (LV) distribution feeder extracted from the New South Wales distribution system is considered. All the households in the LV feeder are assumed to have rooftop PV units with integrated battery storage devices. A typical $12 \mathrm{kWh}$ Valve Regulated Lead Acid battery is used for simulation. Energy storage devices are modeled incorporating the non-linear voltage versus SoC characteristics and the effect of internal resistance, as described in [21]. The LV feeder under study is shown in Fig. 9. The results shown correspond to the PV output fluctuations in household no. 28 ( $\mathrm{HH} 28$ ) connected to phase $a$, bus 10 of the LV feeder.

The PV output data correspond to the irradiance profile of the $18^{\text {th }}$ of March, 2010, captured by NREL in the Oahu Island, Hawaii [4]. For simplicity, constant inverter efficiency $(89.5 \%)$ is used in the simulations. To select the ramp-rate threshold limit to apply the inverse characteristic in (13), $R_{\text {lim }}$ is selected by observing the ramp-rate during slow variation of $P_{\mathrm{DC}}$ from 7:00 hours to 9:00 hours. During this time frame, more than $99 \%$ of the ramp-rates were less than $3 \mathrm{~W} / \mathrm{sec}$, as

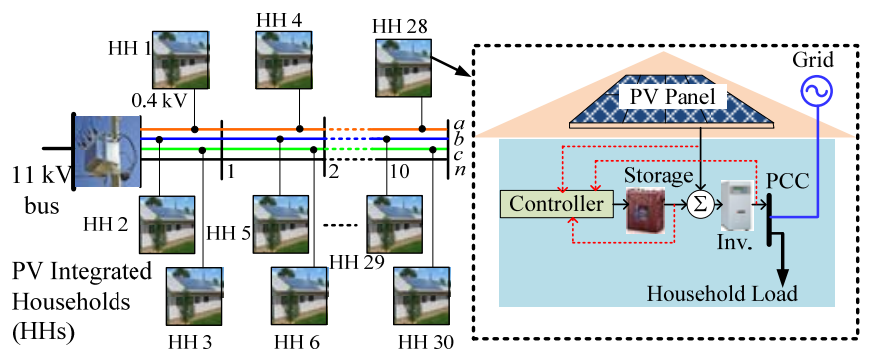

Fig. 9. The LV test feeder with the PV-storage integrated systems.

shown in Fig. 10(a). Therefore, to allow for this variation, $\mathrm{RR}_{\lim }$ is set to a higher value of $5 \mathrm{~W} / \mathrm{sec}$. MARR $\mathrm{max}_{\max }$ in (14) is also set to $5 \mathrm{~W} / \mathrm{sec}$ for the same purpose. Simulation trials have been run using a range of $0.1 \leq \gamma \leq 50$. For $\gamma \leq 1$, fluctuation mitigation performance does not improve much, whereas with $\gamma>1$, deterioration of the fluctuation mitigation performance appears with $\gamma \geq 20$. The value of $\gamma$ has been selected as 5 (with Watt to $\mathrm{kW}$ conversion: 0.005 ).
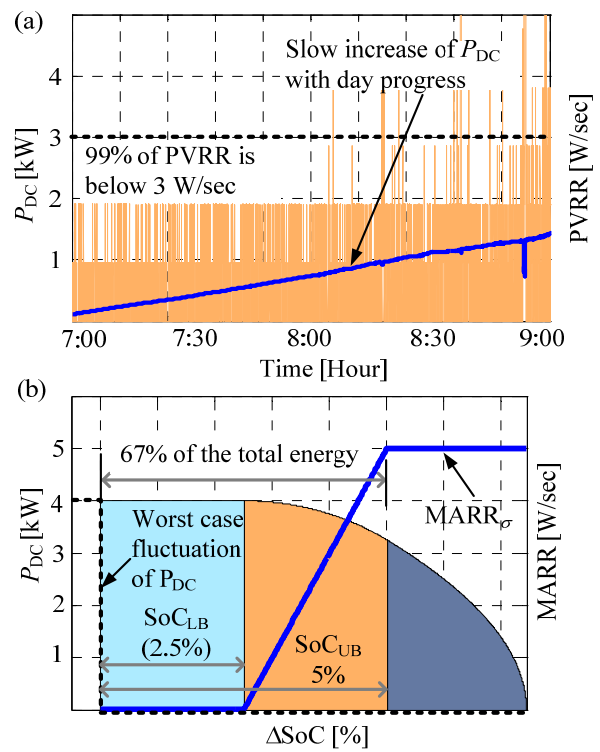

Fig. 10. PVRR during slow variation with the progress of the day. (a) Energy used to control the worst case fluctuation and MARR ${ }_{\sigma}$ characteristic.

The storage devices are allowed to operate between a typical range of $40 \%$ to $100 \%$ SoC. To allow for charging and discharging for ramp-rate control, $\mathrm{SoC}_{\mathrm{ref}}$ is set to $70 \%$, which is at the mid-point of the allowable range of SoC. The SoC bands, $\mathrm{SoC}_{\mathrm{LB}}$ and $\mathrm{SoC}_{\mathrm{UB}}$, are selected considering the worst case fluctuation of $P_{\mathrm{DC}}$ from the rated value ( $4 \mathrm{~kW}$ for the PV systems in the network under study) to zero at the worst-case ramp-rate of $\mathrm{P}_{\mathrm{DC} \text {-rated }} / \mathrm{sec}$ and after the fall, $P_{\mathrm{DC}}$ does not recover due to a continuous cloudy period. The $P_{\mathrm{DC}}$ profile with the storage support is shown in Fig. 10(b), where the ramp-rate control is performed according to (14), as shown using the $\mathrm{MARR}_{\sigma}$ profile. $\mathrm{SoC}_{\mathrm{LB}}$ is set to $2.5 \%$ which corresponds to the amount of energy that can control the ramp-rate at the value of $\mathrm{MARR}_{\min }$ for about 5 minutes which is sufficient for bringing emergency power online or 
disconnecting sensitive loads safely. $\mathrm{SoC}_{\mathrm{UB}}$ is set to $5 \%$ which accounts for about $67 \%$ of the total energy used for bringing $P_{\mathrm{DC}}$ to zero at a controlled ramp-rate. The parameters used for the simulation of the proposed ramp-rate control strategy are given in Table-I in the Appendix. Initially, the results of the quasi-steady state simulations using $1-\mathrm{sec}$ resolution data are presented to investigate the validity of the strategy over a daylong variation. Later, dynamic simulation results in milliseconds time-frame are presented.
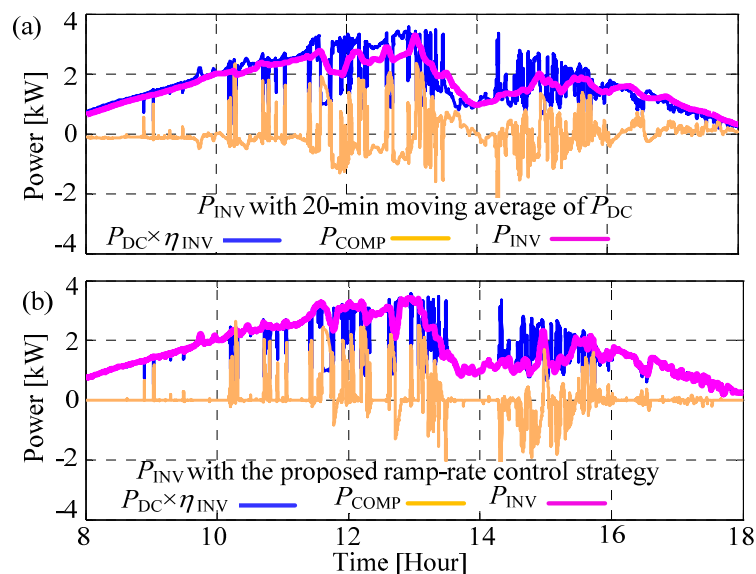

Fig. 11. Mitigation of PV output fluctuation. (a) Using moving average. (b) Using the proposed ramp-rate control strategy.

PV panel DC power, $P_{\mathrm{DC}}$ (multiplied by the inverter efficiency), the storage compensation power $P_{\text {COMP }}$, and the inverter output $P_{\mathrm{INV}}$ are shown in Fig. 11(a) and 11(b) for the moving average control and the proposed strategy, respectively. For moving average control, a 20-min moving average [9] of $P_{\mathrm{DC}}$ is used.

In general, both of the methods (moving average and the proposed approach) can mitigate the fluctuations in PV output, as observed from Fig. 11. However, detailed investigations reveal the specific advantages of the proposed approach. Fig. 12(a) shows $P_{\mathrm{DC}}$ and $P_{\mathrm{INV}}$ profiles in a shorter window, from 10:00 hour to 13:00 hour. According to the proposed strategy, $P_{\mathrm{INV}}$ tracks $P_{\mathrm{DC}}$ when the ramp-rate of $P_{\mathrm{DC}}$ does not exceed the desired ramp-rate at that time. Therefore, the proposed strategy does not need to operate the storage at all the times. In contrast, (10) suggests that the moving average method needs to continue the storage operation due to the past history of $P_{\mathrm{DC}}$, even if it is not necessary as the ramp-rate is within

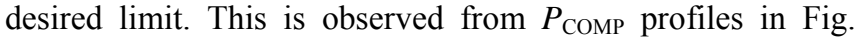
12(b) for the moving average methods and 12(c) for the proposed approach. In Fig. 12(c), zero values of $P_{\text {COMP }}$ are highlighted using dotted circular shapes. Examining the $P_{\text {COMP }}$ profiles it is found that according to the proposed strategy, the storage device operates for about 50\% less time in the 10 hours period (from 8:00 to $18: 00 \mathrm{hrs}$ ) in comparison to the moving average method. This can contribute to increase the lifetime of a battery storage device.

The percentage ratio of $P_{\mathrm{INV}}$ to $P_{\mathrm{DC}}$, based on the profiles in Fig. 12(a), is compared between the proposed approach and moving average method in Fig. 13. Due to the dependency of previous $P_{\mathrm{DC}}$ values, $P_{\mathrm{INV}}$ obtained from the moving average method is different (lower) than $P_{\mathrm{DC}}$, even during the periods when $P_{\mathrm{DC}}$ exhibits very low fluctuation. In contrast, the proposed approach tracks $P_{\mathrm{DC}}$ in those periods and therefore, the $P_{\mathrm{INV}}$ to $P_{\mathrm{DC}}$ ratio is higher using the proposed approach, as compared to the moving average method.
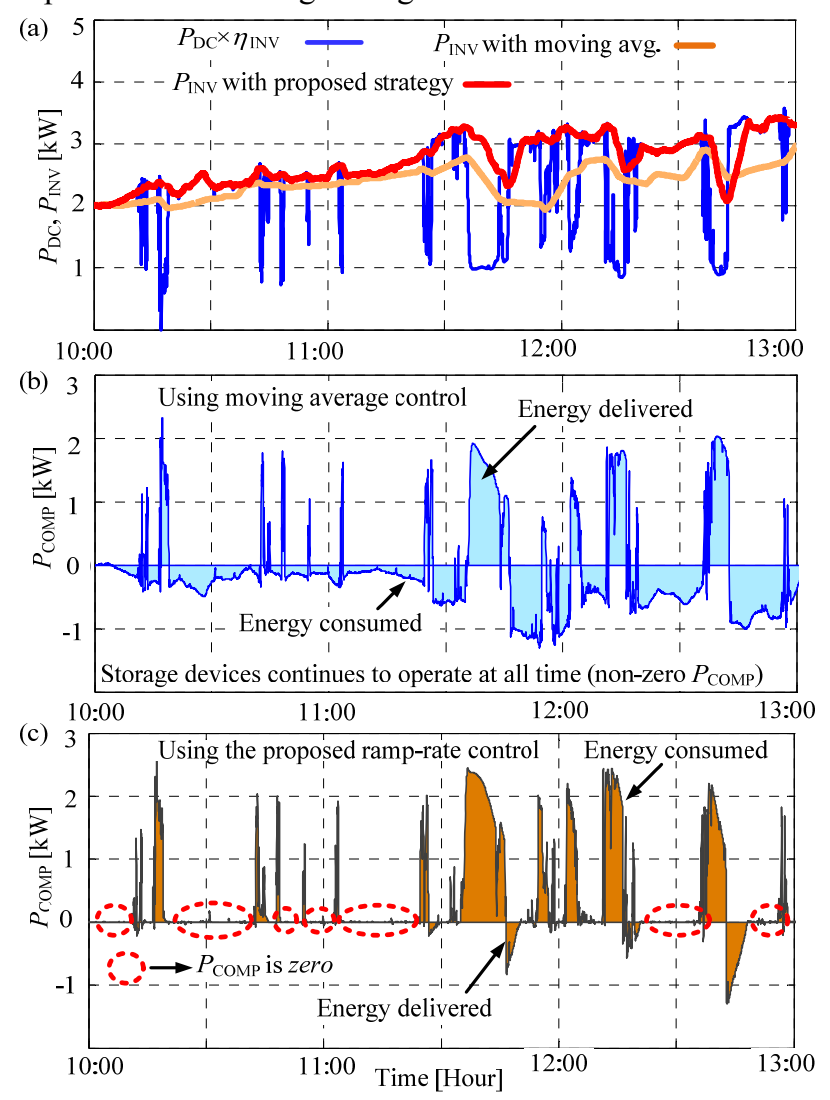

Fig. 12. Mitigation of PV output fluctuation. (a) $P_{\mathrm{DC}}$ and $P_{\mathrm{INV}}$ profiles. (b) $P_{\text {COMP }}$ with moving average control. (c) $P_{\text {COMP }}$ with the proposed strategy.

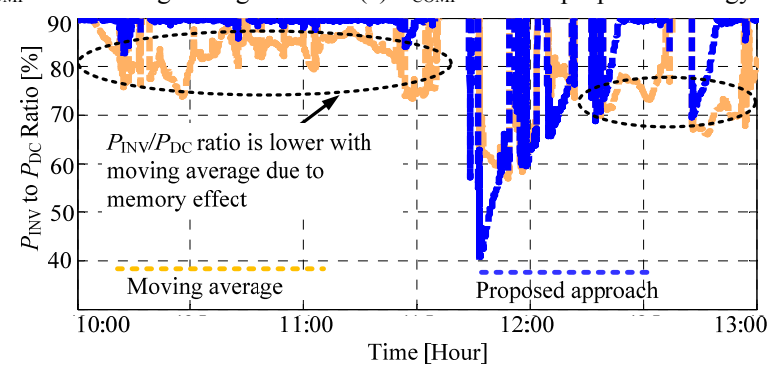

Fig. 13. $P_{\mathrm{DC}}$ to $P_{\mathrm{INV}}$ ratio.

The ramp-rate profiles of $P_{\mathrm{DC}}$ and $P_{\mathrm{INV}}$ from 10:00 hour to 13:00 hour are shown in Fig. 14(a); the ramp-rates of $P_{\text {INV }}$ can be controlled within a specified limit by operating the storage device according to the proposed strategy. The ramp-rates of $P_{\text {INV }}$ with 20-min moving average control of storage device are compared with those obtained using the proposed strategy in Fig. 14(b) for the time period when the maximum negative and positive ramp-rates in $P_{\mathrm{DC}}$ appeared. For reference, the ramp-rate of $P_{\mathrm{DC}}$ is also included in Fig. 14(b). During the negative fluctuation of $P_{\mathrm{DC}}$ with a ramp-rate of $-1.767 \mathrm{~kW} / \mathrm{sec}$, the proposed strategy controls the $P_{\mathrm{INV}}$ ramp-rate at -0.0028 $\mathrm{W} / \mathrm{sec}$ which comes from the inverse characteristic in (13). With the 20-min moving average, the ramp-rate of $P_{\mathrm{INV}}$ is $1.485 \mathrm{~W} / \mathrm{sec}$, which is not controlled at this value; rather it is produced as a result of the previous $P_{\mathrm{DC}}$ samples over the last 
$20 \mathrm{~min}$ period. During the positive ramping event at 1.725 $\mathrm{kW} / \mathrm{sec}$, the ramp-rate with the proposed strategy is 0.0029 $\mathrm{W} / \mathrm{sec}$ which is controlled using (13), whereas, with the moving average it is $0.0183 \mathrm{~W} / \mathrm{sec}$, which is not actually controlled to this value. Although the moving average method provides significant fluctuation mitigation at the expense of operating the storage device all the time, the proposed strategy provides better mitigation during the time of fluctuation with a high ramp-rate (such as the one shown in Fig. 14).
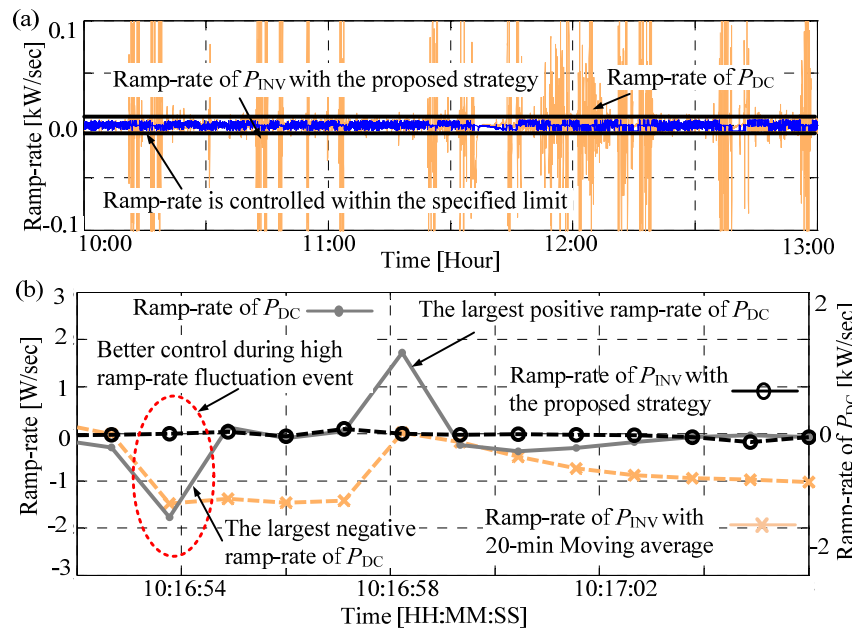

Fig. 14. Ramp-rate control. (a) The ramp-rate profiles of $P_{\mathrm{DC}}$ and $P_{\mathrm{INV}}$. (b) Comparison of the $P_{\mathrm{INV}}$ ramp-rates obtained using the moving average control and the proposed strategy.

The usefulness of the proposed MARR characteristics in (13) and (14) can also be observed in Fig. 15 where the PV output fluctuation mitigation using the proposed inverse MARR characteristic from 12:00 hours to 13:00 hours is compared with a constant MARR value of $5 \mathrm{~W} / \mathrm{sec}$. The proposed inverse MARR and SoC droop based characteristics can mitigate the fluctuation better than a constant MARR value. For reference, the fluctuation mitigation using the 20min moving average is also included in Fig. 15.

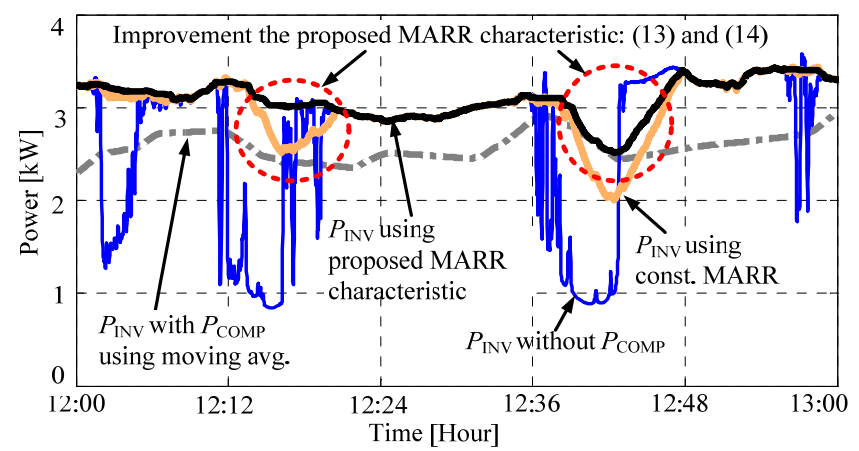

Fig. 15. The usefulness of the proposed inverse characteristic in the improvement of fluctuation mitigation.

The PCC voltage profile at household no. 28 ( $\mathrm{HH} \mathrm{28)} \mathrm{of}$ the test feeder from 10:00 hours to 13:00 hours is shown in Fig. 16(a). For reference, $P_{\text {COMP }}$ profile is also shown in Fig. 16(b). When sharp decrease in PCC voltage appears as a result of sudden decrease in PV output, energy storage device is discharged to control the high negative ramp-rates. This action mitigates the associated voltage dips. Again, when sharp rise in PCC voltage appears due to sudden increase in PV output, energy storage device is charged to control the positive ramp- rates and this action mitigates the sharp voltage rise as well. Without the proposed ramp-rate control strategy, the voltage ramp-rate at $10 \mathrm{hr}: 16 \mathrm{~min}: 54 \mathrm{sec}$ (when the largest negative ramp-rate in the PV output appeared) is $-9.3 \mathrm{~V} / \mathrm{sec}$ and at $10 \mathrm{hr}$ : $16 \mathrm{~min}: 58 \mathrm{sec}$ (when the largest positive ramp-rate in PV output appeared) is $9.1 \mathrm{~V} / \mathrm{sec}$. Controlling the ramp-rate of PV output using the proposed strategy, the PCC voltage ramp-rate is reduced to less than $0.1 \mathrm{mV} / \mathrm{sec}$.

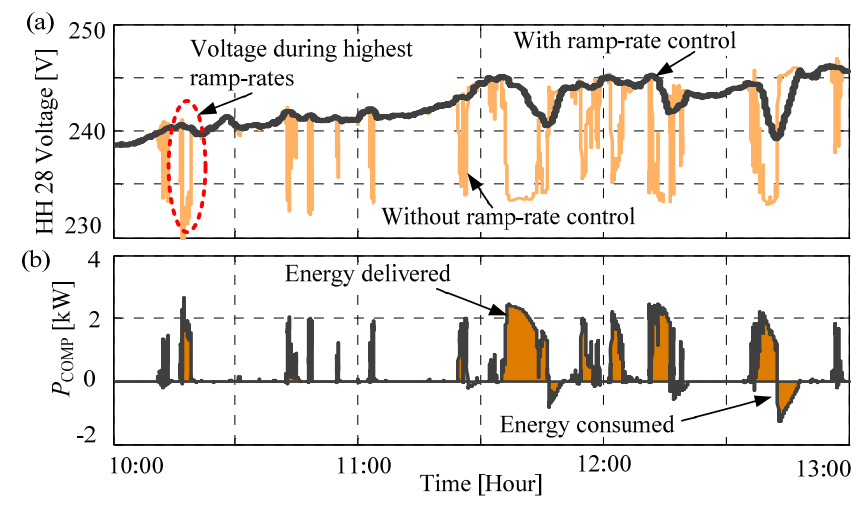

Fig. 16. Mitigation of PCC voltage fluctuation using the proposed strategy. (a) PCC voltage profile. (b) $P_{\text {СомP }}$ profile.

The validation of the proposed strategy in a dynamic environment is tested using the proposed PV-storage integrated system model using 1 millisecond time step and the results are presented in Fig. 17. The largest ramp-rate observed in the PV output data used for the daylong simulation is used for this purpose. The dynamic simulation is performed with the data shown in Table II in the Appendix.

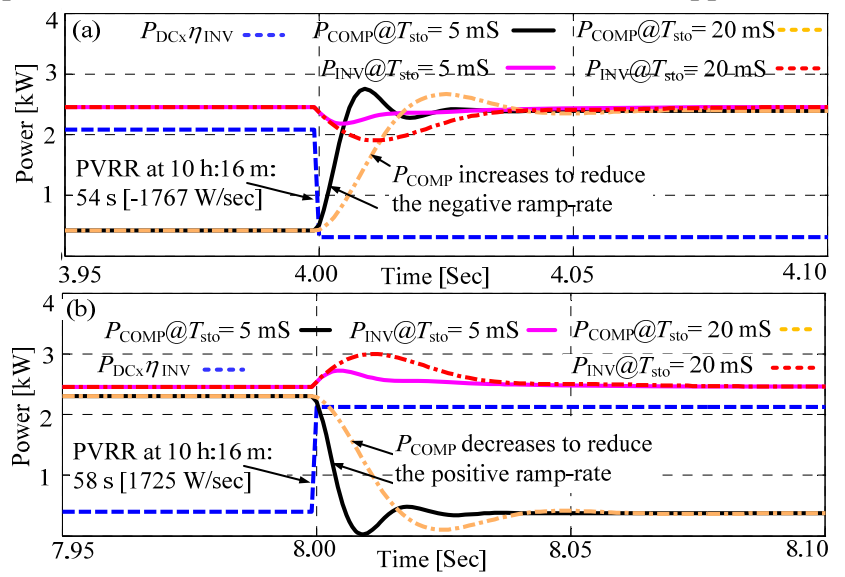

Fig. 17. Performance analysis using the proposed dynamic model. (a) Negative ramp-rate control; (b) Positive ramp-rate control.

The PV output decreases at a ramp-rate of $-1.767 \mathrm{~kW} / \mathrm{sec}$ at $10 \mathrm{hr}: 16 \mathrm{~min}: 54 \mathrm{sec}$. Fig. 17(a) shows that following the negative ramp-rate of $P_{\mathrm{DC}}, P_{\mathrm{COMP}}$ increases within a few milliseconds time to increase the $P_{\mathrm{INV}}$ at the level that maintains the desired ramp-rate $\mathrm{MARR}_{\rho}$ specified at the time. After 4 seconds time, the $P_{\mathrm{DC}}$ again increases with a ramp-rate of $1.725 \mathrm{~kW} / \mathrm{sec}$ at $10 \mathrm{hr}: 16 \mathrm{~min}: 58 \mathrm{sec}$. Fig. 17(b) shows that following the positive ramp-rate of $P_{\mathrm{DC}}, P_{\mathrm{COMP}}$ decreases to the level necessary to maintain the desired ramp-rate of $P_{\mathrm{INV}}$ at that time. The impact of the storage time constant $T_{\text {sto }}$ is also shown in Fig. 17; $P_{\mathrm{INV}}$ with $T_{\text {sto }}$ of 5 milliseconds settles down faster and with less swing as compared to the $P_{\text {INV }}$ with $T_{\text {sto }}$ of 20 milliseconds. Therefore, a storage device 
with a fast response time is necessary for a satisfactory mitigation of the fluctuation.

\section{EXPERIMENTAL RESULTS}

An experimental set-up with a controllable DC power source simulating the PV panel DC power, an Ultratech $12 \mathrm{~V}$ 7Ah sealed lead-acid battery, a charge/discharge controller (Model: CM3024Z), a PowerBright 400W, 12V DC to 220V AC inverter (Model: ERP400-12), and a Chroma programmable AC/DC electronic load (Model: 63804) is used to verify the main concept of the proposed approach. The experimental set-up is shown in Fig. 18. The waveforms are captured using an Agilent Infiniivision (Model: DSO7034A) series oscilloscope.

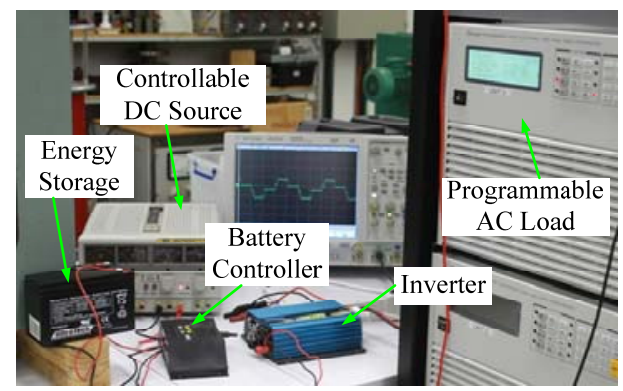

Fig. 18. Experimental set-up for verification of the proposed strategy.

A segment of the real PV generation profile used to obtain the simulation results is used for the experiment where the highest negative and positive ramp-rate of $P_{\mathrm{DC}}$ is included. A scale factor is used to scale down the simulation data to comply with the ratings of the equipment. The data points obtained from the simulation are shown in Fig. 19(a) that shows that from the $2^{\text {nd }}$ to the $3^{\text {rd }}$ data point, the PV output decreases at a ramp-rate of $-55 \% / \mathrm{sec}$ of the rated output, then remains at low values of less than $15 \%$ of the rated output from the $3^{\text {rd }}$ to $6^{\text {th }}$ data point. Then it increases at a ramp-rate of $53 \% / \mathrm{sec}$ of the rated output from the $6^{\text {th }}$ to the $7^{\text {th }}$ data point. With the proposed control approach, $P_{\text {COMP }}$ is controlled using (13) from the $2^{\text {nd }}$ to the $3^{\text {rd }}$ data points and from the $6^{\text {th }}$ to $7^{\text {th }}$ data points (ramping events). From the $3^{\text {rd }}$ to the $6^{\text {th }}$ data point (post-ramping event), $P_{\text {COMP }}$ is controlled using (14). As a result of controlling $P_{\text {COMP }}$ according to the proposed strategy, the ramp-rate of $P_{\mathrm{INV}}$ is maintained at such a low value over the period of fluctuation $\left(1^{\text {st }}\right.$ to $7^{\text {th }}$ data point $)$ that $P_{\text {INV }}$ remains nearly constant, as shown in Fig. 19(a). The captured waveforms of the DC source current, $I_{\mathrm{DC}}$, the battery current, $I_{\mathrm{COMP}}$, and the inverter current $I_{\mathrm{INV}}$ at the points $\left(\mathrm{P}_{1}\right)$, $\left(\mathrm{P}_{2}\right)$, and $\left(\mathrm{P}_{3}\right)$ identified in Fig. 19(a), are shown in Fig. 19(b). The time differences among the data points are represented using dashed lines. The decrease of $I_{\mathrm{DC}}$ from $\mathrm{P}_{1}$ to $\mathrm{P}_{2}$ caused by cloud passing is compensated by the increase of $I_{\mathrm{COMP}}$ and therefore, $I_{\mathrm{INV}}$ remains nearly constant from $\mathrm{P}_{1}$ to $\mathrm{P}_{2}$. The increase of $I_{\mathrm{DC}}$ from $\mathrm{P}_{2}$ to $\mathrm{P}_{3}$, when the cloud passing is over, makes $I_{\mathrm{COMP}}$ to decrease. Therefore, $I_{\mathrm{INV}}$ remains nearly constant from $\mathrm{P}_{2}$ to $\mathrm{P}_{3}$. The results from this experiment indicate that the proposed strategy would be able to control the ramp-rate of $P_{\mathrm{INV}}$ by appropriately controlling the $P_{\mathrm{COMP}}$ support.

(a)

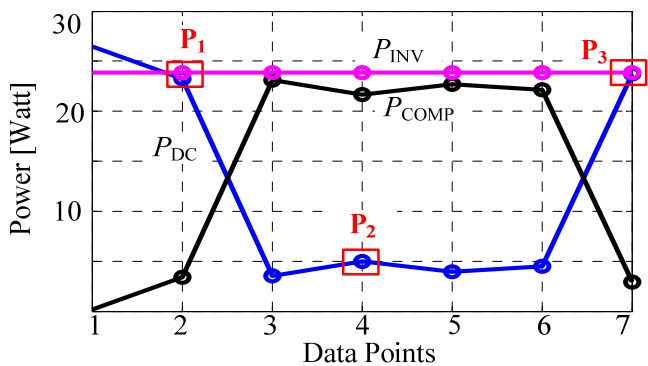

(b)

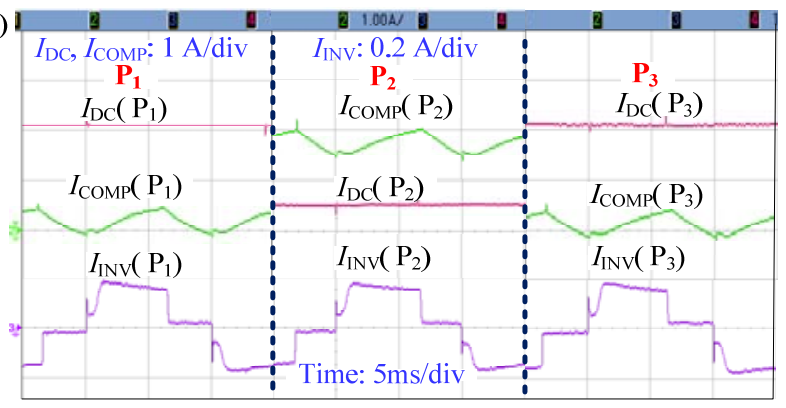

Fig. 19. Experimental results (a) Data points for experimental verification. (b) Captured current waveforms for points $\mathrm{P}_{1}, \mathrm{P}_{2}$ and $\mathrm{P}_{3}$.

\section{CONCLUSION}

This paper has proposed a new approach for PV inverter ramp-rate control using an integrated energy storage device. Unlike the traditional moving average method, which is biased by the previous values and does not directly control the ramprate at a desired level, the proposed method can limit the ramp-rate within a desired level. An inverse characteristic of the desired ramp-rate with the PV panel output ramp-rate is proposed to improve the fluctuation mitigation performance during the ramping event. Once the ramping event is over, the desired ramp-rate is switched to a droop characteristic with SoC so that the available capacity is taken into account while controlling the ramp-rate. Simulation results show that the mitigation of the PV output fluctuation achieved by the proposed ramp-rate control strategy is comparable to those obtained using the moving average method, while not using the energy storage all the time. Also, during very high ramprate events, the proposed strategy can provide tighter control of the ramp-rate due to the inverse characteristic. The mitigation of voltage fluctuation in weak networks caused by PV output fluctuation using the proposed method is also demonstrated. The validity of the proposed strategy has been verified in a dynamic environment using a dynamic model of the PV-storage integrated system developed in this paper. The results from a laboratory experiment using a PV inverter, a battery storage system, and an electronic load demonstrates that the proposed approach is able to control the PV inverter ramp-rate by providing appropriate support from the storage device. 


\section{APPENDIX}

TABLE I

SiMULATION PARAMETERS OF THE PROPOSED CONTROL STRATEGY

\begin{tabular}{l|l}
\multicolumn{1}{c|}{ Parameter } & \multicolumn{1}{c}{ Value } \\
\hline \hline$\left|\mathrm{RR}_{\text {lim }}\right|, \gamma$ & $5 \mathrm{~W} / \mathrm{sec}, 0.005$ \\
\hline $\mathrm{SoC}_{\mathrm{ref}}, \mathrm{SoC}_{\mathrm{LB}}, \mathrm{SoC}_{\mathrm{UB}}, \mathrm{DB} B_{\mathrm{SoC}}$ & $70 \%, 2.5 \%, 5 \%, 2.5 \%$ \\
\hline $\mathrm{MARR}_{\min }, \mathrm{MARR}_{\max }, D B_{\mathrm{MARR}}$ & $\mathrm{MARR} \rho, 5 \mathrm{~W} / \mathrm{sec},\left(5-\mathrm{MARR}_{\min }\right)$ \\
\hline $\mathrm{SoC}_{\max }, \mathrm{DoD}_{\max }$ & $100 \%, 40 \%$ \\
\hline \hline
\end{tabular}

TABLE II

PARAMETERS USED FOR DYNAMIC SIMULATION

\begin{tabular}{l|c}
\multicolumn{1}{c}{ Parameter } & Value \\
\hline \hline$T_{\text {inv }}, T_{\text {sto }}, T_{\text {meas }}$ & $20 \mathrm{mS}, 5 \mathrm{mS}, 3 \mathrm{mS}$ \\
\hline$K_{\mathrm{P}}, K_{\mathrm{I}}$ & $2.30,470$ \\
\hline \hline
\end{tabular}

\section{REFERENCES}

[1] W. Jewell and R. Ramakumar, "The Effects of Moving Clouds on Electric Utilities with Dispersed Photovoltaic Generation," IEEE Transactions on Energy Conversion, vol. EC-2, pp. 570-576, 1987.

[2] E. C. Kern, E. M. Gulachenski, and G. A. Kern, "Cloud effects on distributed photovoltaic generation: slow transients at the Gardner, Massachusetts photovoltaic experiment," IEEE Transactions on Energy Conversion, vol. 4, pp. 184-190, 1989.

[3] C. Trueblood, S. Coley, T. Key, L. Rogers, A. Ellis, C. Hansen, and E. Philpot, "PV Measures Up for Fleet Duty : Data from a Tennessee Plant Are Used to Illustrate Metrics That Characterize Plant Performance," IEEE Power and Energy Magazine, vol. 11, pp. 33-44, 2013.

[4] J. Johnson, B. Schenkman, A. Ellis, J. Quiroz, and C. Lenox.Sandia National Laboratories. Initial Operating Experience of the La Ola 1.2 MW Photovoltaic System [Online]. Available: http://energy.sandia.gov/wp/wp-content/gallery/uploads/SAND20118848 Lanai DOE Report FINAL.pdf

[5] NREL. 1-Second Global Horizontal Irradiance Oahu, Hawaii [Online] Available: http://www.nrel.gov/midc/oahu_archive/

[6] S. Abdollahy, A. Mammoli, F. Cheng, A. Ellis, and J. Johnson, "Distributed compensation of a large intermittent energy resource in a distribution feeder," in IEEE PES Innovative Smart Grid Technologies, Washington, DC, USA, 24-27 Feb. 2013, pp. 1-6.

[7] S. Sayeef, S. Heslop, D. Cornforth, T. Moore, S. Percy, J. K. Ward, A Berry, and D. Rowe.CSIRO. (June 2012). Solar intermittency: Australia's clean energy challenge. Characterising the effect of high penetration solar intermittency on Australian electricity networks. [Online] Available: https://publications.csiro.au/rpr/download?pid=csiro EP121914\&dsid=DS1

[8] H. Sugihara, K. Yokoyama, O. Saeki, K. Tsuji, and T. Funaki, "Economic and Efficient Voltage Management Using Customer-Owned Energy Storage Systems in a Distribution Network With High Penetration of Photovoltaic Systems," IEEE Transactions on Power Systems, vol. 28, pp. $102-111,2013$

[9] N. Kakimoto, H. Satoh, S. Takayama, and K. Nakamura, "Ramp-Rate Control of Photovoltaic Generator With Electric Double-Laye Capacitor," IEEE Transactions on Energy Conversion vol. 24, pp. 465473, 2009

[10]T. Kinjo, T. Senjyu, N. Urasaki, and H. Fujita, "Output levelling of renewable energy by electric double-layer capacitor applied for energy storage system," IEEE Transactions on Energy Conversion, vol. 21, pp. 221-227, 2006

[11]T. Monai, I. Takano, H. Nishikawa, and Y. Sawada, "A collaborative operation method between new energy-type dispersed power supply and EDLC," IEEE Transactions on Energy Conversion, vol. 19, pp. 590-598, 2004.

[12]K. S. Tam, P. Kumar, and M. Foreman, "Enhancing the utilization of photovoltaic power generation by superconductive magnetic energy storage," IEEE Transactions on Energy Conversion, vol. 4, pp. 314-321, 1989.

[13] S. Rahman and K. S. Tam, "A feasibility study of photovoltaic-fuel cel hybrid energy system," IEEE Transactions on Energy Conversion, vol. 3 , pp. $50-55,1988$.

[14] T. D. Hund, S. Gonzalez, and K. Barrett, "Grid-Tied PV system energy smoothing," in Photovoltaic Specialists Conference (PVSC), Honolulu, HI, USA, 20-25 Jun., 2010, pp. 2762-2766.
[15] J. Traube, L. Fenglong, D. Maksimovic, J. Mossoba, M. Kromer, P. Faill, S. Katz, B. Borowy, S. Nichols, and L. Casey, "Mitigation of Solar Irradiance Intermittency in Photovoltaic Power Systems With Integrated Electric-Vehicle Charging Functionality," IEEE Transactions on Power Electronics, vol. 28, pp. 3058-3067, 2013.

[16]S. G. Tesfahunegn, Ø. Ulleberg, P. J. Vie, and T. M. Undeland, "PV Fluctuation Balancing Using Hydrogen Storage-a Smoothing Method for Integration of PV Generation into the Utility Grid," Energy Procedia, vol. 12, pp. 1015-1022, 2011.

[17]L. Xiangjun, H. Dong, and L. Xiaokang, "Battery Energy Storage Station (BESS)-Based Smoothing Control of Photovoltaic (PV) and Wind Power Generation Fluctuations," IEEE Transactions on Sustainable Energy, vol 4, pp. 464-473, 2013

[18]C. J. Coe, A. N. Hurst, M. I. Hardin, M. C. Such, and R. T. Jennings.(Nov. 2011, US Patent 20110273129). Managing Renewable Power Generation [Online]. Available: https:/docs.google.com/ viewer?url=www.google.com/patents/US20110273129.pdf

[19] C. A. Hill, M. C. Such, C. Dongmei, J. Gonzalez, and W. M. Grady, "Battery Energy Storage for Enabling Integration of Distributed Solar Power Generation," IEEE Transactions on Smart Grid, vol. 3, pp. 850$857,2012$.

[20]A. Ellis, D. Schoenwald, J. Hawkins, S. Willard, and B. Arellano, "PV output smoothing with energy storage," in Photovoltaic Specialists Conference (PVSC), Austin, TX, USA., 3-8 Jun., 2012, pp. 1523-1528.

[21] M. J. E. Alam, K. M. Muttaqi, and D. Sutanto, "Mitigation of Rooftop Solar PV Impacts and Evening Peak Support by Managing Available Capacity of Distributed Energy Storage Systems," Accepted for a future issue of IEEE Transactions on Power Systems.

[22]H. Chen, T. N. Cong, W. Yang, C. Tan, Y. Li, and Y. Ding, "Progress in electrical energy storage system: A critical review," Progress in Natural Science, vol. 19, pp. 291-312, 2009.

[23]B. Espinar and D. Mayer.International Energy Agency. July 2011. The role of energy storage for mini-grid stabilization [Online]. Available: http://www.iea-pvps-task11.org/HTMLobj-187/Act_24_Final.pdf

[24] Mathworks. (Oct. 2013). PID tuning algorithm for linear plant mode [Online]. Available: http://www.mathworks.com.au/help/control/ref/ pidtune.html

\section{BIOGRAPHIES}

M J E Alam (S'10) obtained his B Sc and M Sc degree in EEE from Bangladesh University Engineering and Technology in 2005 and 2009, respectively. At present, he is working towards $\mathrm{PhD}$ degree at the University of Wollongong, New South Wales, Australia. His research interest includes modeling and analysis of power systems considering the impacts of distributed and renewable energy resources. He has worked in the electric utility industry in Bangladesh for 4.5 years

K M Muttaqi (M'01, SM'05) received the Ph.D. degree from Multimedia University, Malaysia, in 2001. Currently, he is an Associate Professor at the School of Electrical, Computer, and Telecommunications Engineering, University of Wollongong, Wollongong, Australia. He is an Associate Editor of IEEE Transactions on Industry Applications. His special fields of interests include distributed generation, renewable energy, power system planning, intelligent grid, and power system reliability.

D Sutanto (SM'89) obtained his BEng. (Hons) and PhD from the University of Western Australia. He is presently the Professor of Power Engineering at the University of Wollongong, Australia. His research interests include power system planning, analysis and harmonics, FACTS and Battery Energy Storage systems. He is a Senior Member of IEEE. He is currently the IEEE IAS Area Chair for Region 10 (Asia Pacific). 